\section{Zum 90. Geburtstag von Prof. Dr. Wolfgang Keitel}

Sicher kann an dieser Stelle abermals eine lange Aufzählung der Auszeichnungen, Ehrungen, Preise und Ehrenmitgliedschaften, welche Prof. Wolfgang Keitel im Laufe der Jahre verliehen wurden, stehen. Jedoch möchten wir hier an erster Stelle die Persönlichkeit dieses außergewöhnlichen Arztes und Wissenschaftlers vorstellen und uns an einige humorvolle Episoden aus seinem Berufsleben erinnern, an der eine Vielzahl von Freunden, Kollegen, Doktoranden und Habilitanden mit großer Freude teilhaben durften.

Prof. Keitel wurde am 02. April 1931 in Neumark, Kreis Merseburg, geboren. Nach dem Medizinstudium an der Martin-Luther-Universität in Halle bis 1955 ging er für seine internistische Facharztausbildung an die Medizinische Akademie Magdeburg, wo er 1965 habilitierte und 1976 zum Professur berufen wurde. Von 1969 an begründete er die Rheumatologische Abteilung der Fachklinik Vogelsang, die er sehr erfolgreich zu einem führenden Zentrum der Rheumatologie erweiterte und aus der bis zu seiner Emeritierung 1995 zahlreihe hervorragende Rheumatologen hervorgingen.

Wegbegleiter beschreiben Prof. Keitel als einen Meister der Effizienz, den jede Minute der Arbeitszeit, welche der Wissenschaft und „seiner Klinik“ entgeht, wurmte. Eine solche Hingabe für den Beruf erwartete er auch von seinen Assistenten, deren Ausbildung Prof. Keitel stets zur Ehrensache erklärte.

Als geradezu legendär wurde die „Zugangsvisite“ beschrieben. In dieser Veranstaltung wurden im Beisein sämtlicher Kollegen sowie der Pflegeleitung, der Physiotherapie sowie der Ergotherapie die Neuzugänge dem Chefarzt vorgestellt. Eine Möglichkeit zum fundierten Austausch und einer wirk- lich ganzheitlichen Patientenbetreuung, die sich heutzutage leider kaum noch umsetzen ließe.

Ebenfalls bedeutsam war die „Chefambulanz“. Diese Sprechstunden wurden oft von zahlreichen Gastärzten besucht und beinhaltete nach jeder Patientenvisite nachfolgend ein Frage- und Antwortspiel mit Examenscharakter.

Ein weites Ereignis war die „Röntgenvisite“. Da sich das Vertrauen von Prof. Keitel in die Kompetenz der Radiologen in seinem Fachgebiet in Grenzen hielt, wurden einmal wöchentlich sämtliche Röntgenaufnahmen der Klinik im Kollegenkreis diskutiert und sofort in die Maschine der Sekretärin diktiert. Die Kombination von engem Raum, Dunkelheit und dazu stickiger Luft hielt niemanden davon ab, gerade dieser hochinteressanten Veranstaltung beizuwohnen.

Eine Anekdote, von der Prof. Keitel auch gern heute noch mit einem verschmitzten Lächeln, voller Stolz berichtet: Er war auch ein Pionier der Computeranwendung in der DDR! So gelang es ihm mithilfe einer langjährigen Rheumapatientin schon zum Ende der 1980iger Jahre unter Umgehung sämtlicher Boykott-Maßnahmen aus Ost und West einen Computer in der Klinik Vogelsang zu installieren.

Wer denkt, dass sich Prof. Wolfgang Keitel ins Altenteil zurückgezogen hat, irrt. Auch heute kann man dem Professor regelmäßig in der Medizinhistorischen Sammlung im Klinikum Vogelsang, die er als einen sehr beliebten Weiterbildungsort für Interessierte und Patienten nach seiner Emeritierung aufgebaut hat, bei der Beschreibung detaillierter historischer Zusammenhänge erleben.

Da die große Feier dieses Jahr durch ein kleines Virus ausgebremst wurde, gratulieren wir auf diesem Wege ganz herzlich und danken Prof. Wolfgang Keitel für all das, was er für seine Patienten, Kollegen, seine Klinik und nicht zuletzt auch für diese Zeitschrift getan hat.

Ad multos annos!

Dein Carlo Weimann, Katrin Richert und alle Dir sehr verbundenen Kollegen und Wegbegleiter 